Portland State University

PDXScholar

\title{
Family Psychoeducation in Clinical High Risk and First- Episode Psychosis
}

\author{
William R. McFarlane \\ Tufts University Medical School \\ Sarah Lynch \\ Ryan P. Melton \\ Portland State University, rymelton@pdx.edu
}

Follow this and additional works at: https://pdxscholar.library.pdx.edu/rri_facpubs

Part of the Other Psychiatry and Psychology Commons, and the Social Work Commons Let us know how access to this document benefits you.

\section{Citation Details}

McFarlane, William R.; Lynch, Sarah; and Melton, Ryan P., "Family Psychoeducation in Clinical High Risk and First- Episode Psychosis" (2012). Regional Research Institute. 23.

https://pdxscholar.library.pdx.edu/rri_facpubs/23

This Post-Print is brought to you for free and open access. It has been accepted for inclusion in Regional Research Institute by an authorized administrator of PDXScholar. Please contact us if we can make this document more accessible: pdxscholar@pdx.edu. 


\section{FAMILY PSYCHOEDUCATION IN CLINICAL HIGH RISK AND FIRST-EPISODE PSYCHOSIS}

Originally published in: "Family Psychoeducation in Clinical High Risk and FirstEpisode Psychosis” Adolescent Psychiatry, 2(2) pp. 182-194 


\title{
FAMILY PSYCHOEDUCATION IN CLINICAL HIGH RISK AND FIRST-EPISODE PSYCHOSIS
}

\author{
WILLIAM R. McFARLANE, M.D. \\ Maine Medical Center Research Institute \\ Tufts University Medical School \\ Columbia University, College of Physicians and Surgeons \\ 22 Bramhall Street \\ Portland, Maine 04012 \\ U.S.A. \\ mcfarw@mmc.org \\ SARAH LYNCH, L.C.S.W. \\ Maine Medical Center \\ 295 Park Avenue \\ Portland, ME 04102 \\ lynchs@mmc.org \\ RYAN MELTON, L.P.C., A.C.S. \\ Early Assessment \& Support Team \\ 1660 Oak St. Suite 230 \\ Salem OR 97301 \\ rmelton@eastcommunity.org
}




\begin{abstract}
$70 \%$ of those who will have an episode of psychosis will have done so by age 25 (Kirkbride et al., 2006). Data from clinical trials of intervention during the clinical high risk period of psychosis have determined that the mean age is in mid-adolescence, 16-18 years of age (Amminger et al., 2010; W. R. McFarlane et al., 2010; McGlashan et al., 2006). For those reasons, early intervention inherently involves adolescents, and by extension their parents and other family members and supports. Regarding the type of intervention, it is relevant that the current empirically-derived standard of treatment for schizophrenia, as concluded by the Agency for Health Care Policy and Research survey of the treatment outcome literature, includes family psychoeducation, supported employment, assertive community treatment and antipsychotic medication,; i.e., a combination of psychosocial and pharmacologic interventions (A. F. Lehman et al., 2004; A.F. Lehman et al., 1998). Combinations of all four of these treatments, as in Family-aided Assertive Community Treatment (FACT), achieve very low rates of relapse, substantial reductions of symptoms and remarkable functional outcomes, particularly in the domain of competitive employment (Cook et al., 2005; William R. McFarlane et al., 2000; William R. McFarlane, Dushay, Stastny, Deakins, \& et al., 1996; W. R. McFarlane, Stastny, \& Deakins, 2002; William R. McFarlane, Stastny, Deakins, Dushay, \& Link, 1995). Furthermore, a large comparative study of outcomes in community settings found that psychoeducational multifamily groups were more effective than single-family psychoeducation specifically in the first episode and in high-risk-for relapse cases, suggesting that particular psychosocial treatments may be especially effective in early phases of illness (Fjell et al., 2007; W. R. McFarlane et al., 1995; Petersen et al., 2005).
\end{abstract}


Keywords: Clinical high-risk, early intervention, family intervention, family psychoeducation, multifamily groups, prodromal psychosis, psychosis, schizophrenia.

\author{
Abbreviations: \\ ES: Education Specialist \\ IPS: Individual Placement and Support \\ EE: expressed emotion \\ FACT: Family-aided Assertive Community Treatment \\ FEP: first episode psychosis \\ FPE: family psychoeducation \\ MFG: multifamily group \\ PMFG: psychoeducational multifamily group
}

Disclosures: Dr. McFarlane, Ms Lynch and Mr. Melton are faculty of the PIER Training Institute, LLC, which provides on-request training and consulting services for evidence-based practices and early psychosis programs.

Acknowledgements: The authors are the principal investigator and deputy directors for Early Detection and Intervention for the Prevention of Psychosis Program, a National Program sponsored by the Robert Wood Johnson Foundation, grant number 58920. 


\section{Biological and social processes during the early stages of psychosis:}

\section{amplifying interactions}

The stress-diathesis or stress-vulnerability model provides a widely-accepted, empirically-supported framework for describing the relationships among provoking agents (stressors), vulnerability and symptom formation (diathesis) and outcome (Zubin \& Spring, 1977; Zubin, Steinhauer, \& Condray, 1992). A key longitudinal study conducted in Finland compared adoptees with and without biological risk for schizophrenia adopted into families with either high or low environmental stress over a twenty one year span. The study showed that adoptees with both genetic risk and a high stress environment were at high risk for developing schizophrenia. Those with genetic risk and low expressed emotion were at no greater risk for developing schizophrenia than those with no genetic risk (P. Tienari, Wahlberg, \& Wynne, 2006; P. A. Tienari et al., 2004). Thus, a vulnerable person, whose inborn tolerance for stress is incompatible with exposure to either internally- or externally-generated stimulation, may be thrown into a first or a recurring episode of illness. Put simply, biology provides the necessary pre-condition, but both biological susceptibility and environmental stress cause illness onset or exacerbation. Therefore, this principle underlies the Biosocial Hypothesis:

Major psychotic disorders are the result of the continual interaction of specific biologic disorders of the brain with specific psychosocial and other environmental factors.

The treatment described here is based on a simple and plausible theory: the first episode of psychosis is a relapse in an evolving disorder, and the proximal causes of the first episode are the same as those in later relapses. Therefore, treatments that prevent relapse by counteracting those proximal causes could as well prevent or ameliorate the first episode. 
Family Psychoeducation (FPE) is an evidence-based practice for the treatment of schizophrenia, bipolar disorder and other psychotic disorders. A theoretical model for the efficacy of FPE in the early phase consists of the following: First episodes of psychosis are induced in biologically vulnerable individuals by major stresses imposed by role transitions and other life events, social isolation/rejection, family conflict and exasperation, separation from family of origin and stigma. Family intervention alters these critical environmental variables by reducing ambient social and psychological stresses, building barriers to excess stimulation and buffering the effects of negative life events. Thus, family intervention should have an independent preventive effect on the development of the initial episode, primarily by reducing ambient stimuli and stress. As will be shown below, the evidence for such a preventive effect is promising, and even stronger for preventing relapse and improving functioning after a first episode. We will focus in this article on psychosis in schizophrenia spectrum and Axis I mood disorders, as well as the clinical high risk period prior to onset. For this article we define family more broadly to include extended family and support network.

In essence, FPE prevents or treats the first episode by counteracting the very stresses that appear to be the final common pathway for psychoses across the three principal diagnoses of schizophrenia, bipolar disorder and major depression. FPE for at-risk individuals and those who have experienced a first episode may be effective without antipsychotic drugs (especially when refused by patient/family) or at lower doses. The main targets of FPE and Psychoeducational Multifamily Groups (PMFGs) are expressed emotion, the effects of stigma, communication deviance and attention dysfunction in patients and relatives, social network variables and life events. Further, including the effects of psychotic disorders on the family yields an interactive, 
positive-feedback-based model for the final stages of onset, rather than a simpler linear-causal model.

\section{Effects of psychosis on the family}

Because some family members of patients with established psychotic disorders may share sub-clinical forms of similar deficits and abnormalities, including attentional abnormalities, negative symptoms, hypomania and depression, a treatment for very early stages of psychosis must be designed to compensate for some of those difficulties (Lichtermann, Karbe, \& Maier, 2000). Those deficits lead to diminished coping ability, which is required in abundance to provide a therapeutic influence on the affected family member. The structure and organization of most families that are affected by psychotic disorders undergo a variety of changes, including alienation of siblings, exacerbation or even initiation of marital conflict, severe disagreement regarding support versus behavior control, and even divorce. Almost every family undergoes a degree of demoralization and self-blame, which may be inadvertently reinforced by some clinicians (Lefley, 1996). Limited experience suggests that these effects begin during the clinical high risk period, as soon as the young person begins to manifest deterioration in performance, clinical high risk symptoms or signs of social withdrawal(Lencz, Smith, Auther, Correll, \& Cornblatt, 2004). Family members are mystified by the often dramatic emotional, cognitive and behavior changes that they are seeing, and react in a wide variety of ways, from anger to denial to profound anxiety and worry. They may seek help, but are often told that nothing is wrong or that nothing can be done. The result is a slow-moving crisis that allows for neither guidance nor resolution. 
Expressed Emotion (EE)

Expressed emotion (EE) is a measure of family communication that rates levels of criticism, positive remarks, hostility, warmth, and emotional over-involvement (G.W. Brown, Birley, \& Wing, 1972; Kuipers, 1994). EE and its impact on relapse rates have been studied repeatedly over the last four decades, yielding the conclusion that high levels of EE are strongly associated with, and predictive of, the exacerbation or relapse of symptoms (G.W. Brown, et al., 1972; Leff \& Vaughn, 1981; Vaughn \& Leff, 1976; Vaughn, Snyder, Jones, Freeman, \& Falloon, 1984). In an extensive meta-analysis, Bebbington and Kuipers (1994) cite the overwhelming evidence, among 25 studies representing 1346 patients in 12 different countries, for a predictive relationship between high levels of expressed emotion and relapse of schizophrenia and bipolar disorders. Butzlaff and Hooley (1998) match these results in another meta-analysis of 27 studies with a higher association between EE and relapse in samples containing more chronically ill clients (Butzlaff \& Hooley, 1998; J. Hooley \& Richters, 1995). This suggests that the client may be more sensitive to $\mathrm{EE}$ as the illness process progresses and also that family EE increases with length and severity of illness.

High EE in early psychosis families was characterized by emotional over-involvement, which is a predictable response to parental anxiety and confusion during the onset of psychosis (W. R. McFarlane \& Cook, 2007; Meneghelli et al., 2011). It is important to note that the prospectively validated predictors of the onset of schizophrenic psychosis in vulnerable adolescents are close analogues of EE (Goldstein, 1985; P. A. Tienari, et al., 2004). In an observational study looking at family burden in first-episode psychosis, Gonzales-Blanch et al (2010) also found that family subjective and objective burden were correlated with emotional over-involvement rather than criticism. McFarlane and Cook (2007) and Meneghelli (2011) 
found that parents of young people in the early stages of psychosis showed more warmth and lower levels of criticism, hostility and rejection. This suggests that in early stages family members are supportive but deteriorate into increasing levels of EE as the patient's illness progresses?

Intervention in the early stages of illness may prevent the onset, as well as the negative impact, of high EE. Attribution--the relatives' beliefs about the causes of illness-related behavior--has also been associated with expressed emotion. Relatives described as critical or hostile misperceive the patient as responsible for unpleasant, symptomatic behavior, whereas more accepting relatives saw identical behaviors as characteristic of the illness itself (Brewin, MacCarthy, Duda, \& Vaughn, 1991; J. M. Hooley \& Licht, 1997; William R. McFarlane \& Lukens, 1998). If confronted by such symptoms without knowledge of the illness, family members may respond with over involvement, increased intensity and criticism. Parents who blamed themselves for their child's illness scored higher on emotional over-involvement (Peterson \& Docherty, 2004). Thus, a reasonable hypothesis is that a large degree of family “dysfunction” in the clinical high risk phase is secondary to the deterioration that has already occurred in the affected young person, while also interacting with the adolescent's vulnerability, thereby amplifying symptoms and other functional sequelae of the accelerating biologic process. Standard practice provided to concerned, anxious parents during this phase is all too frequently the "wait and see" approach, which does nothing to interrupt this downward spiral, and often exacerbates the family members' anxiety, sense of helplessness, and in some cases their tendencies to criticize and reject.

\section{Effects of Stigma}


Stigma is often associated with a withdrawal of social support, demoralization, and loss of self-esteem, and can have far-reaching effects on daily functioning (Duckworth, Nair, Patel, \& Goldfinger, 1997). As Link and his colleagues (Link, Mirotznik, \& Cullen, 1991) observed, stigma had a strong continuing negative impact on well-being, even though proper diagnoses and treatment improved symptoms and levels of functioning over time. Effects of stigma include withdrawal and isolation on the part of family members, which in turn is associated with a decrease in social network size and emotional support, increased burden, diminished quality of life and exacerbations of medical disorders (Johnson, 1990). Many families of clinical high risk youth see fears of stigma and social rejection as the dominant factor influencing their treatment decisions. Self-imposed stigma and labeling change the manner in which family members view themselves and their child, and tend to reduce the likelihood that early signs will be addressed and treatment sought or accepted. Franz et al. (2010) found that stigma, and fear of the label of mental illness, may result in treatment delay until symptoms are more overt. Consistent with hypothesized impact of stigma, a study of family members of persons admitted for a first episode concluded at least half of the parents concealed the hospitalization from friends and colleagues (Phelan, Bromet, \& Link, 1998).

\section{Communication deviance and attention dysfunction in parents and relatives}

Communication deviance, a measure of distracted or vague conversational style, has been consistently associated with schizophrenia and bipolar disorder (Miklowitz et al., 1986; D.

Miklowitz et al., 1991, May; Singer \& Wynne, 1985). Communication deviance has predictive validity for psychosis in families of at risk adolescents, which means that other family members may be at risk (Goldstein, 1985; P. A. Tienari, et al., 2004). Studies that are more recent have demonstrated that it is correlated with cognitive dysfunction in the relatives, of the same type, 
but lower severity, as is seen in persons with schizophrenia (Wagener, Hogarty, Goldstein, Asarnow, \& Browne, 1986). This suggests that even during the clinical high risk period some family members will have difficulty holding a focus of attention, with important implications for treatment design. This factor is an example of the "double jeopardy" model: a young person in the clinical high risk state may have inborn cognitive and attentional dysfunction exacerbated by heritable family communicational difficulties. Once severe functional and performance deterioration begins, the family's coping skills may be inadequate to deal with the increasing complexity and stresses inherent in the situation.

\section{Diminishing social networks}

The available evidence across several severe and chronic illnesses indicates that ongoing access to social contact and support prevents the deterioration of such conditions, and improves their course (Penninx, Kriegsman, van Eijk, Boeke, \& Deeg, 1996). Persons with schizophrenia and their families are more socially isolated than are their peers (Garrison, 1978; Hammer, 1981; Pattison, Llama, \& Hurd, 1979). Family members of the most severely ill patients are often isolated, preoccupied with, and burdened by, the patient. Brown, et al (1972) showed that 90\% of the families with high expressed emotion were small and socially isolated. They demonstrated a strong association between size and availability of a friendship and family network and the onset and duration of depression (G.W. Brown \& Harris, 1978). Social support buffers the impact of adverse life events (Lin \& Ensel, 1984), predicts medication compliance (Fenton, Blyler, \& Heinssen, 1997; Heller, Roccoforte, Hsieh, Cook, \& Pickett, 1997), attitude and behavior toward treatment in general, schizophrenic relapse over four years, buffering of life events (Hultman, Wieselgren, \& Ohman, 1997) and quality of life of mentally ill adults living in the community (Becker et al., 1998). Availability of social support to the family and the density 
of the social network were associated with successful patient community tenure and incidence (Macdonald, Jackson, Hayes, Baglioni, \& Madden, 1998; Mattsson, Topor, Cullberg, \& Forsell, 2008; Veling, Hoek, \& Mackenbach, 2008) and with subjective burden experienced by relatives and hospitalization rates (Solomon \& Draine, 1995a, 1995b).

A key finding relating to the clinical high risk phase is that social network size is lower than normal prior to illness onset and decreases during the first episode and continues to decrease with each corresponding episode (Anderson, Hogarty, Bayer, \& Needleman, 1984; Lipton, Cohen, Fischer, \& Katz, 1981; Tolsdorf, 1976). Families report having withdrawn from their own social circles, and vice versa (Biegel, Sales, \& Schulz, 1991). The implication is that social isolation is a risk factor and target of intervention in early intervention.

\section{Life events}

Major life events and transitions can lead to destabilization and relapse. Steinberg and Durrell (Steinberg \& Durell, 1968) found that the vast majority (nearly 80\%) of first episodes in an Australian sample occurred after separation from home and family or upon entering college or the military. From early to late in the modern era of psychiatric research, life events have continued to be associated with, or predictive of, relapse in all three major psychotic disorders, major depression (G. W. Brown, 1998; Kendler, 1998; Malkoff Schwartz et al., 1998; Takeuchi et al., 1998; van Os et al., 1994), schizophrenia (Bebbington et al., 1993; Chafetz, Havassy, \& Arean, 1997; Das, Kulhara, \& Verma, 1997; Hirsch et al., 1996; Hultman, et al., 1997; Leff, 1994; Nuechterlein et al., 1994; van Os, et al., 1994) and bipolar disorder (Hays, Krishnan, George, \& Blazer, 1998; Malkoff Schwartz, et al., 1998; van Os, et al., 1994). When measured, there is a tendency for life events to be more impactful when the patient is less vulnerable on a neurocognitive, genetic or severity of illness basis (Bebbington, et al., 1993; Malkoff Schwartz, 
et al., 1998; Pallanti, Quercioli, \& Pazzagli, 1997; van Os, et al., 1994), when the illness is at an earlier stage (Hays, et al., 1998; Steinberg \& Durell, 1968) and when medication is not being used (Hirsch, et al., 1996; Nuechterlein, et al., 1994). For young adults and adolescents the most potent events tend to be those that involve loss of supportive social ties, especially separation from, or death of, family members, romantic/marital losses for women and occupational disruptions for men.

\section{Models of natural and therapeutic causation}

These critical variables of EE, stigma, communication deviance, social network size, and life events increase risk for psychosis through a limited number of mechanisms. They are all potential targets for psychosocial treatment, especially in the form of psychoeducational multifamily groups. There exists a general sensitivity to external stimulation and a discrepancy between current stimulus complexity and cognitive capacity. In essence, normal levels of stress, information and stimulation lead to abnormal, if not catastrophic, responses in individuals with actual or potential disorders. Sub-clinical cognitive deficits, effects of psychosis on the family and characteristic coping styles combine to contribute to external illness-generated stresses that can induce a spiraling and deteriorating process that ends in a major psychosis.

The psychoeducational framework assumes that these stress factors can be countered or ameliorated by family- and social-network intervention. It has also been assumed that once the person experiences the first episode of psychosis, antipsychotic, mood-stabilizing or antidepressant medication will also be required to achieve a full therapeutic effect, by counteracting abnormal functioning in one or several neurotransmitter systems. A key question is whether intervention at several levels, to counteract stressors prior to onset of psychotic symptoms, might allow medication to be reserved only for those cases in which the young person deteriorates 
symptomatically despite otherwise successful intervention directed at those environmental variables.

\section{Developmental, conceptual and social processes during the at-risk}

\section{and first episode stage}

This and the following sections describe the developmental, conceptual and social context within which this family-oriented treatment approach is designed to be therapeutic.

\section{Adolescence Brain Development and Cognitive Capacity}

Psychotic disorders tend to strike initially before the prefrontal cortex is fully myelinated, differentiated, pruned and mature, inducing a partial arrest of cognitive development during late adolescence (Sun et al., 2009). Therefore, judgment, problem-solving, abstraction, executive decision-making, social skills and career-planning functions are impaired at the point that they become essential to mastering a modern post-industrial environment. Clinicians and families need to find empathic and non-coercive means to support the affected person to cope with the condition somewhat conservatively. This dilemma is reminiscent of the problems encountered when trying to help adolescents with emerging diabetes to make all the adjustments needed to manage their illness.

\section{Adolescent Developmental Tasks and Onset of Psychosis}

At the time clinical high risk and early psychosis occurs, affected individuals are consolidating their identity, making meaningful the non-familial world, differentiating from and re-negotiating relationships with their family of origin, developing skills to master the external 
environment and establishing a more or less independent life and lifestyle (Erikson, 1968). All of these processes are usually arrested and often reversed early in the course of an acute schizophrenic episode. Identity development is compromised from the very beginning of the clinical high risk period, and perhaps earlier. Psychosis imposes new meanings on the perceived world, most of them quite negative and unstable. It also impairs one's ability to sort through the varieties and nuances of meaning and interpretation of external reality (McGorry, McFarlane, et al., 1995). Unfortunately, the standard treatment also distorts identity, often promoting the adoption of a "patient” or, worse, “mental patient” identity. Psychosis and the traditional mental health treatment system response erode mastery and, therefore, the preconditions for self-esteem. Nevertheless, the normal developmental tasks remain the goals of almost all persons and their families in spite of the episode, which complicates education efforts and recommendations to create a temporary asylum from stress and demands in the community. In addition, there will be tangible losses to person and family by adopting a set of temporarily retrenched ambitions and activities in the attempt to reverse the psychosis. The task is to educate and train both patient and family in order to restore the capacity to interpret reality and prevail over it. The educational program needs to be individualized to maximize confidence and mastery.

\section{Adolescent Affective Development and Interactions with Onset}

Adolescents and young adults are often more affectively labile and impulsive than they might be in their mid-adulthood (Dahl, 2001). Again, that affects how one must approach the issue of education and adherence. Denial, erratic treatment follow through, impulsive counteradaptation behavior and hostility toward clinicians and family are very common during this period. However, given the common presentation of the psychoses as alterations of affect and mood, the situation during the clinical high risk period is particularly complex. For families, the 
confusion between affective instability and adolescent moodiness is further complicated by the possible influences of a psychosis and its inherent emotional lability. For instance, is the depression that is so often the first sign of an impending psychotic or mood disorder actually a reaction to a psychosocial stressor or a romantic crisis, and how does a family member reliably differentiate the alternatives?

\section{Family Interactions during Onset}

As a generalization, the family of the person having an initial psychotic experience is in transition from cohesion to differentiation. Family interactions vacillate normally from overcontrol to complementarity, from dependence to independence, from authority struggles to the symmetry of adult-to-adult relationships (Carter \& McGoldrick, 1989). Incipient psychosis disrupts this process drastically. If the illness progresses to disability, the normal momentum toward autonomy is lost and replaced by forced regression to complementarity, i.e., care-taking and dependence. This is usually exaggerated by confusion and misattribution about the cause of the mental deterioration and by misdirected and often contradictory attempts to alleviate symptoms and despair in the ill relative.

In a study of young people at clinical high risk for psychosis, family problem solving interactions were correlated with symptomatic and functional outcomes after six months. Adolescents who demonstrated constructive problem solving and parents who demonstrated constructive communication were correlated with the young person’s improved social functioning at six months. Additionally, conflictual communication was correlated with an increase in positive symptoms of psychosis at six months (O'Brien et al., 2009). These results suggest that family intervention focused on problem solving and communication skill building will reduce symptoms and increase functioning. 
Effects of Information about Diagnosis and Prognosis

Unlike the usual response to education in well-established schizophrenia, parental and familial responses to the news of an impending psychotic or mood disorder is often perceived as unwelcome or even not useful. Patient and family, for different reasons, are frightened by these disorders and their effects, and parents, at least, are even more frightened by the potential prognosis. Even when the diagnosis is certain, the announcement needs to be made with great sensitivity to the impact that this will have on all participants. Clinicians need to emphasize that the only reliable means for dealing with these fears is to work collaboratively with the team to keep the underlying process under control and to plan for dealing with it for an extended period into the future. This is a clear case when planning for the worst is the best antidote to the worst occurring: "If you can accept the core predisposition or constitutional vulnerability, you can often overcome it substantially. By ignoring it, you risk that symptoms will return, often very shortly, to overwhelm you."

\section{Family psychoeducation: applications in established, first-episode}

\section{and clinical high-risk disorders}

By 1980, theories about the biological basis for schizophrenia and other psychotic disorders were gaining wider support and recognition. The FPE model builds on these theories, defining psychotic disorders as brain disorders sensitive to the social environment. This form of treatment is seen as bimodal, influencing both the disease, through medication, and the social environment, through techniques which deliberately reduce stimulation, rate of change and complexity to tolerable levels. FPE provides relevant education, training and support to family members and others who in turn provide support to the patient. 
FPE reduces relapse and hospitalization rates for schizophrenia while improving symptoms and social and vocational functioning (I. R. Falloon, 2003; William R. McFarlane, Dixon, Lukens, \& Lucksted, 2003; Murray-Swank \& Dixon, 2004; Pitschel-Walz, Leucht, Bauml, Kissling, \& Engel, 2001). FPE has also demonstrated effectiveness in early intervention work targeting major psychotic disorders. Further, psychoeducational multifamily groups (PMFGs) independently reduce negative symptoms (Dyck et al., 2000; W. R. McFarlane, E. Lukens, et al., 1995). Those treated in early first episode or the high-risk stage of illness are more responsive to treatment and have fewer residual and negative symptoms.

The cumulative record of efficacy for family intervention (not family therapy) is remarkable. Outcome studies by Goldstein (1978), Leff (1989), Falloon et al (1985a, 1985b), Hogarty et al (1991), Tarrier et al (1989), Schooler and Keith (1997), and Randolph (1994) report a reduction in annual relapse rates for medicated, community based patients of as much as $40 \%$, using a variety of educational, supportive and behavioral techniques. The average relapse rates in these studies stand at just under $15 \%$ for family approaches and $40 \%$ for individual treatment, without family involvement. This effect equals the reduction in relapse in medicated vs. unmedicated patients in most drug maintenance studies (G. Hogarty \& Ulrich, 1977; Schooler, Levine, \& Severe, 1980). In over 40 controlled clinical trials, the track record for symptomatic, relapse and functional superiority of family over non-family based psychosocial treatments is clear: it is effective, in nearly any country, population, socioeconomic environment, class, gender or ethnic group, when applied in schizophrenia. A meta-analysis of four studies demonstrates a difference in two-year relapse rates between psychoeducational multiple family groups and routine treatment at 28\% vs. 64\% across four studies (Baucom, Shoham, Mueser, Daiuto, \& Stickle, 1998). Emerging evidence demonstrates similar results for bipolar and major 
depressive disorder (G.I. Keitner et al., 2002; G. I. Keitner \& Miller, 1993; D. J. Miklowitz, Frank, \& George, 1996; D. J. Miklowitz \& Goldstein, 1997).

The psychoeducational multiple family group (PMFG) reduces relapse to even lower frequencies and enhances vocational and social rehabilitation outcomes (W. R. McFarlane, Link, Dushay, Marchal, \& Crilly, 1995; W. R. McFarlane, E. Lukens, et al., 1995). In fact, in multifamily groups the relapse rates fall between $9.5 \%$ and $12.5 \%$ per year, compared to $16 \%$ 35\% for single-family format and those patients with prior episodes. An interaction with treatment was demonstrated among families with high expressed emotion at baseline: relapse rates were significantly lower in multifamily groups than in the low expressed emotion subgroup, whereas those rates were higher in single-family treatment, as expected. For patients having multiple risk factors, the difference at two years is stark: $9 \%$ vs. 56\%. A study with a similar design found very low relapse rates over four years (12.5\% per year), with the lowest rates and best functional outcomes occurring in multifamily groups among younger patients who entered the study during their first episode, again compared to the same family intervention provided in a single-family format (20\% per year) (W. R. McFarlane, B. Link, et al., 1995).

In a review of randomized control trials of early intervention services (including family intervention) for people ( $\mathrm{n}=800$ ) with early symptoms of psychosis, early intervention services reduced hospitalization, relapse rates and improved access to and engagement in treatment. The trials assessing family intervention showed that participants receiving family intervention were less likely to relapse or be hospitalized than patients in standard treatment (Bird et al., 2010). In an Australian randomized control trial, first-episode patients were assigned to family intervention and cognitive-behavioral therapy (CBT) or standardized case management. Early results at seven months indicate that the relapse rate was significantly lower in the family intervention 
treatment group (Gleeson et al., 2010). Many of the studies of established disorders included large proportions of first-episode cases. The sample in the first study of this type had 69\% of the cases having their first episode (Goldstein, Rodnick, Evans, May, \& Steinberg, 1980). There were no relapses in the cohort that received family crisis therapy during the six months of the trial, significantly lower than in the cohort without family involvement. A long-term follow-up disclosed remarkably good outcomes in the period from three to six years after intervention (Kopeikin, Marshall, \& Goldstein, 1983). In a study in schizophrenia of differential effects of multi-family group (MFG) and single-family (SFT) and forms of the same psychoeducational treatment method, the preponderance of the better outcomes observed for multifamily groups was among those having their first hospitalization (W.R. McFarlane, 2002; W. R. McFarlane, E. Lukens, et al., 1995). The difference in two-year relapse rates between the two treatment formats was $19 \%$ vs. $44 \%$ ( $p=0.02)$, vs. 32-35\% for those with more chronic disorders. Positive symptoms at baseline significantly influenced relapse outcome in MFGs and SFT: for those who were only partially remitted, the difference was marked: 19\% in MFGs vs. 51\% in SFT. In MFGs the best outcome occurred in those with the greatest degree of residual schizophrenic symptoms $(\mathrm{p}<.01)$.

Thus, like early drug treatment, family intervention appears to have especially positive outcomes in first-episode patients, and multifamily groups are superior to single-family format, when the treatment method is held constant between formats. Based on findings, multifamily group is the preferable format within which to deliver family psychoeducational treatment for early intervention and, by extrapolation, for trial as a treatment in clinical high risk cases.

\section{Family-aided Assertive Community Treatment (FACT)}


For those at risk, early intervention can not only prevent conversion to a full psychotic disorder but also treat any symptoms already present, as well as impaired cognitive, social, and occupational functioning. It can also alleviate family distress, reducing the risk that family interactions will become a risk factor. Early intervention programs can reduce duration of untreated psychosis (DUP) for individuals who already meet criteria for a psychotic disorder. Reducing DUP can ameliorate the impact psychosis can have on symptomatology, functioning, trauma, social networks, and the community at large. The exact treatment package to achieve optimal outcomes remains unknown. However, elements have been specifically identified to provide a holistic, easily accessible and non-stigmatizing intervention to a multidimensional condition. Those elements include: (1) outreach and community education to identify people at risk and reduce duration of untreated psychosis, (2) family and individual psychoeducation to reduce confusion and conflict and provide problem-solving skills, (3) in-vivo counseling, (4) case management to meet the individual in a safe, non-stigmatizing location as well as develop realworld skills, (5) medications to reduce symptoms, and (6) supported employment/education and cognitive rehabilitation to improve occupational functioning and overall quality of life. The goal of intervention is to prevent or delay the onset of psychosis and to provide optimal treatment to those who are already experiencing psychosis. The approach is designed to take place in tandem with community education and referral-network-organization efforts that will lead to young persons in the 12-30 age range being referred for assessment and treatment. This model of identification and intervention has been used in the TIPS, OPUS, and Early Detection and Intervention for the Prevention of Psychosis Program (EDIPPP) studies (Johannessen, Larsen, McGlashan, \& Vaglum, 2000; W. R. McFarlane, et al., 2010; Nordentoft et al., 2006). It consists of the version of Family-aided Assertive Community Treatment (FACT . It includes: 
a. community education to facilitate referrals and ultimately reduce DUP;

b. individualized, phase-specific and developmentally appropriate engagement strategies;

c. a specialized form of psychoeducational multifamily group;

d. ACT, emphasizing proactive clinical case management, short-term cognitive-psychoeducational therapy for the young person, case accountability (in the form of weekly coordination meetings) and assertive follow-up by the team;

e. $\quad$ low-dose medication, as indicated;

f. $\quad$ substance abuse treatment, as indicated;

g. supported employment and education; and

h. cognitive and sensory assessments completed by occupational therapists.

The early intervention team should arrange treatment for medical disorders and other essential supports, including residential treatment, housing supports, special education, employment, and social skills training. The team in all instances to date consists of clinical specialists from mental health disciplines and from adolescent and/or adult psychiatry.

Because the clinical high risk period and the first episode appear to be more responsive to treatment and have fewer residual and negative symptoms, the value of family-based treatment, specifically PMFG, is that it may work without drugs (when refused by patient/ family) or allow lower and/or tapering doses. Individuals or families that did not benefit in the PMFG approach were shown to do well when family intervention was combined with Assertive Community Treatment (ACT), to create Family-aided ACT (FACT) (W. R. McFarlane, Dushay, Stastny, Deakins, \& Link, 1996), (W. R. McFarlane, P. Stastny, \& S. Deakins, 1992). FACT has now been shown to be more effective than conventional approaches in achieving competitive 
employment (W. R. McFarlane, Dushay, R.A., Deakins, S.M., Stastny, P., Lukens, E.P., Toran, J., Link, B., 2000) and reducing conversion rates. In the first controlled trial of PMFGs and ACT in a clinical high risk sample, the conversion rates over two years were $25 \%$, compared to $48 \%$ in the control (standard care) group (Nordentoft, et al., 2006). The FACT intervention is currently being tested in a clinical high-risk and very early first episode psychosis sample at six national sites, with results expected in 2012.

\section{FACT for clinical high risk and first-episode psychotic disorders}

The psychoeducation multifamily group treatment model described here is designed to assist families directly in coping with the major burdens and stresses during the clinical high risk and psychotic phases of these disorders. Thus, this approach (a) allays anxiety and exasperation; (b) replaces confusion with knowledge, direct guidance, problem-solving and coping skill training; (c) reverses social withdrawal and rejection by participation in a multifamily group that counteracts stigma and demoralization; and (d) reduces anger by providing a more scientific and socially acceptable explanation for symptoms and functional disability. Finally, by explicitly conveying hope and opportunities to assist in treatment and rehabilitation, it relieves the burdens of coping while more fully engaging the family in the treatment and rehabilitation process, and compensating for the expected sub clinical symptoms that many relatives may manifest.

The basic psychoeducational model consists of four treatment stages that roughly correspond to the phases of an episode of schizophrenia, acute mania or severe major depression, from the acute phase through the recuperative and rehabilitation phases. These stages are (1)

Engagement; (2) Education; (3) Re-entry; and (4) Social/Vocational Rehabilitation. Individualized, phase-specific and developmentally appropriate engagement strategies 
Psychosis is often frightening, and even the thought of being diagnosed with such a serious mental health condition may cause a young person to refuse to seek help. Lack of insight may have biological roots resulting in individuals with first episode psychosis not seeking help (Amador \& David, 1998). Regardless of the reason, many individuals with early psychosis do not seek assistance. Early intervention team members meet the youth and family at their level of readiness to form a relationship built on trust. Services are strengths-focused and oriented toward issues young people find relevant, such as getting through school, resolving conflicts, paying off debts, or regaining their proficiency in areas they have previously done well in but in which they are now struggling. It is common for an early intervention team member to work only with the family members until engagement with the individual can be achieved. The work with families can include psychoeducation, crisis planning and brainstorming engagement strategies. Information provided to a family in the early or first episode must be sensitive to the phase and stage of the illness as well as the diagnostic uncertainty that exists (Addington, Collins, McCleery, \& Addington, 2005).

Given the age that psychosis is likely to occur and the need for consistency, services are provided to teens and young adults by the same team. There should be no discontinuity of care or caregiver teams just because a person “ages out” of childhood services. Efforts are made to eliminate this barrier and others with administrative staff. Other barriers that may impact engagement and need attention include: flexibility in hours early intervention staff work, allowance to focus on engagement, and use of developmentally and cultural appropriate technology (email \& text). Contacts with the families and with the newly admitted individuals are initiated within 48 hours after a hospital admission, psychotic crisis and/or confirmation of clinical high risk eligibility criteria. Initial contacts with the patient are deliberately brief and 
non-stressful. Clinical high risk young persons are included in at least one of the engagement sessions, and are excluded from at least one. If the individual is psychotic, they are not included in these sessions, but only engaged in a patient-clinician format. The aim is to establish rapport and to gain consent to include the family in the on-going treatment process.

Families are contacted either during a visit to the hospital or by telephone. They are made aware that the early intervention team member is willing to collaborate with them in helping their relative recover and avoid further deterioration or relapse. The family is asked to join with the early intervention team member in establishing a working alliance or partnership, the purpose of which is to provide the best post-hospital environment for the individual to recover. This phase is typically three to seven single-family sessions and follows the multiple family group format, but more may be required until a sufficient number of families is engaged to initiate a newly formed MFG.

\section{Education}

Once the family is engaged and while the individual is still being stabilized, the family is invited to a workshop conducted by the clinicians who will lead the group and other relevant staff. These six hour sessions are conducted in a formal, classroom-like atmosphere, involving five or six families. Biological, psychological, and social information about psychotic disorders and their management are presented through a variety of formats, such as videos, slide presentations, lectures, discussion and question and answer periods. Information about the way in which the early intervention team member, individual and family will continue to work together is presented. The families are also introduced to guidelines for management of the disorder and the underlying vulnerability to stress and information overload. Persons attend 
these workshops if willing, interested and seemingly able to tolerate the social and informational stress.

In the early intervention version, the early intervention team builds education and information-sharing on each patient and family's unique and evolving experience, as assessed during the engagement process. Psychosis is defined as a serious, reversible and treatable condition, like diabetes. It seems essential to define the problem for families and patients generally, as psychosis, an acute psychotic episode, or a predisposition to psychosis, as opposed to a specific disorder, as is done in the family interventions for established schizophrenia or bipolar disorder (McGorry, Mihalopoulos, et al., 1995). Most families will want to understand the range of possible outcomes--from deterioration and disability to full recovery and continuing remission. However, it is important to be clear about the dangers of assuming prognosis based on diagnosis. The advantage of early intervention will be in promoting an improved prognosis, even with diagnostic uncertainty. The core problem is presented as an unusual sensitivity to sensory stimulation, prolonged stress and strenuous demands, rapid change, complexity, social disruption, illicit drugs and alcohol, and negative emotional experience. As for blame and assigning fault, the team members take an important position: neither the patient nor the family caused that sensitivity.

\section{The Re-entry Phase}

Following the workshop, the clinicians begin meeting twice monthly with the families and person in the MFG format. The goal of this stage of the treatment is to plan and implement strategies to cope with the vicissitudes of a person recovering from an acute episode of psychosis or to facilitate recovery from the clinical high risk state. Major content areas include treatment compliance, stress reduction, buffering and avoiding life events, avoiding street drugs and/or 
alcohol, lowering of expectations during the period of negative symptoms and a temporary increase in tolerance for these symptoms. Two special techniques are introduced to participating members as supports to the efforts to follow family guidelines: formal problem solving and communications skills training (I. R. H. Falloon, Boyd, \& McGill, 1984).

\section{Social and Vocational rehabilitation}

Approximately one year following initiation of treatment, or after an acute episode, most patients begin to evidence signs of a return to spontaneity and active engagement with those around them. This is usually a sign that the negative symptoms are diminishing and the patient can now be challenged more intensively. The focus of this phase deals more specifically with his/her rehabilitative needs, addressing the two areas of functioning in which there are the most common deficits: social skills, and their ability to obtain and maintain employment. Additional efforts to improve functional recovery with people undergoing first-episode psychoses have resulted in the introduction of employment support within the preventive FACT model. The primary goal of employment support is to prevent chronic patterns of disability for this population. Delays in returning to work with first-episode psychosis are common, ranging from 1 to 65 months (Gioia, 2006). Explanations for delays include illness-related factors (e.g., symptoms or medication side effects), non-illness-related factors (e.g., lack of childcare, lack of experience), messages from mental health clinicians and families about not returning to work, and fears related to symptom-return while working. This factor is especially important given the symptoms that affect employment the most are not usually positive symptoms, but negative, and cognitive symptoms that often do not improve with medication adherence but can be moderated with psychosocial accommodations. These themes suggest that work delay does increase the likelihood of disability. Given the stage of identity development during which a major psychotic 
disorder occurs, it may be helpful to use career counseling methods to assist individuals in finding their vocational strengths (Gioia, 2006).

With the recent attention on cognitive rehabilitation as an intervention to specially target cognitive impairments in first-episode psychosis individuals, early intervention programs around the world are exploring cognitive rehabilitation as an auxiliary to employment and education support. Eack et al. (2010) asserted that cognitive enhancement training, a form of cognitive rehabilitation with patients experiencing early schizophrenia, might offer neurobiological protection and enhancement associated with improved long-term cognitive outcomes.

Individual placement and support (IPS) is a form of supported employment and education utilized by the FACT model that emphasizes integration of mental health and career services, rapid search for competitive employment and educational positions, assertive community outreach, a focus on individual employment choice, and ongoing support once employed or enrolled in school. Implementation of an IPS model proportionally increased returning to work or school of first-episode schizophrenia patients by $43 \%$ compared with traditional vocational rehabilitation. IPS also resulted in lower attrition rates by $26 \%$. Both findings were considered significant (Nuechterlein et al., 2005).

\section{Multifamily groups}

The psychoeducational multifamily group (PMFG) can be considered a second generation treatment model that incorporates aspects of the psychoeducational model (Anderson, Hogarty, \& Reiss, 1986), as well as aspects of family behavioral management (I. R. H. Falloon, et al., 1984) and multiple family therapy (W.R. McFarlane \& Dunne, 1991). The synthesis incorporates the advantages of each of its sources and diminishes their negative features, leading to a number of synergistic effects that have been shown to enhance efficacy. Multiple family 
groups address elements of expressed emotion, social isolation, stigmatization and burden directly by education, training and modeling. Some of this effort focuses on modulating emotional expression and clarifying and simplifying communication. However, much of the effectiveness of the approach results from increasing the size and density of the social network, by reducing the experience of being stigmatized, by providing a forum for mutual aid, and by providing an opportunity to hear similar experiences and to find workable solutions.

In the current model, a stable membership of from five to seven families meets with two clinicians on a bi-weekly basis for two years following the onset of an initial episode of psychosis or the identification of a clinical high risk condition, all having previously participated in an educational workshop. Unless psychotic, the patients also attend the group, although the decision to do so is based upon the patient's mental status and susceptibility to the amount of stimulation such a group occasionally engenders. Each session lasts for $1 \frac{1 / 2}{2}$ to 2 hours.

\section{Modifications specific to early intervention}

In the clinical high risk and early phase of the initial episode, there is significantly less diagnostic clarity, one of the key building blocks of the PMFG model for established disorders. Thus, the educational material has been substantially altered to emphasize the general characteristics of sensitivity to stress and stimulation and to base education and informationsharing on the patient and family's unique and evolving experience. Providing treatment quickly and early has been shown to improve outcome. This general theme is then illustrated with a host of ways to hasten recovery and to prevent a recurrence. The guidelines and recommendations center on the theme of reducing stress, creating a set of buffers to protect the young person from unavoidable stresses and carefully implementing a gradual return of functioning, staying below 
the threshold that stimulates symptoms and functional deterioration. There is ample material on early warning signs and indications for seeking crisis assistance. Other modifications include:

1. Individualized and rapid education for each family that takes into account the specific features of the symptom constellation in their affected member. That takes place on an ad hoc basis in the engagement process, followed by a classroom presentation for the MFG members, once they are engaged.

2. Emphasis on transient hyperactivity in some brain areas and some biochemical systems, especially the dopamine and glutamatergic tracts, seems to be acceptable as an explanation.

3. The approach allows for accelerated recovery, reentry and rehabilitation in good prognosis cases. The pace of reentry is guided by clinical status, the subsidence of negative symptoms and the continued remission of positive symptoms.

4. There is less emphasis on reducing life expectations and more emphasis on careful forward progress. This is best phrased as "slow down personal and career advancement, until stability and motivation returns".

\section{Case example}

Alex is a 19-year-old male away at his first year of college in Maine. He experienced some mild depression during high school but thought it was understandable given that his best friend had died in a car accident. Several months ago, Alex heard his name called periodically, but when he checked, no one was calling him. He thought nothing of it until it began happening more frequently. Sometimes he heard a louder male voice when trying to fall asleep at night he tried to make out what the voice was saying but he only caught a word here and there. The voice sounded angry. 
Alex had a strong feeling that something bad was going to happen to him - he sensed a presence in his room at night and continually checked his closet. He began to carry a knife in his pocket for protection. He was more and more uncomfortable in crowds and worried that people were looking at him when out in public. He wondered if this was due to fatigue or smoking pot, which he started doing a few times a week to calm himself.

His girlfriend, Julie, was worried because he did not want to leave his room and began to miss more classes. He was not the same person she met at the beginning of the year. A Social Worker from the program came to speak to the Resident Advisors and Counseling Services at the college about warning symptoms for psychosis and the importance of intervening early. Since Julie is an RA, she learned about some of the symptoms and asked Alex to come with her to a clinic, which led to an assessment with the program.

In his assessment interview, Alex stated "I know these thoughts sound ridiculous, but they feel very real when they are happening”. As they have become more intrusive, he could not pay attention and complete his work. Once admitted to PIER, Alex, his girlfriend and his parents (who live close by) came in to a psychoeducational workshop about early warning symptoms of psychosis, the brain basis of symptoms, and guidelines for recovery. The message was hopeful they heard from a young person age 25 who had graduated from the program and who is now living on her own, in graduate school, and doing well. She had experienced a first episode of psychosis three years earlier.

Alex and his clinician made a treatment plan that initially focused in reducing stress, improving sleep and eating, developing a daily routine and coping skills to manage symptoms. They identified his earliest warning signs - irritability, sleep disturbance and feeling like others are watching him. He was given a 24/7 pager number if he was in crisis or having worrisome 
thoughts. The team discussed Alex's treatment interventions on at least a weekly basis. He met with a social worker for individual therapy and a psychiatrist for medication management. Alex began a low dose of an antipsychotic medication and was given information about how marijuana can cause psychotic symptoms in a vulnerable brain. Alex also learned that his father struggled with depression when he was his age and that his grandmother had experienced psychosis and been hospitalized.

Alex received Occupational Therapy testing which indicated that he is struggling with sensory sensitivity and difficulty with memory, attention and organization. The OT gave some specific recommendations for Alex to help him adjust his environment in order to decrease sensory input and provide him with a system for keeping organized. The Employment/ Education Specialist (ES) helped him share his testing results and possible accommodations with the Office of Support for Students with Disabilities at the college. Alex decided to decrease his course load to two classes and lessen his work study hours for the remainder of the semester.

At multifamily group, he met other young people experiencing the same symptoms and was able to hear from people further along in their recovery say that with treatment, they felt "back to their old selves". Alex's parents were less critical of him for his slip in grades as they understood that he was not just "slacking off". Throughout the course of treatment, he described his mood as stable, though sometimes on the low side. After nine months of treatment with medication, Alex requested a trial off of his medications. This trial occurred over a period of about two months. His parents were extremely worried about Alex stopping his medications. They brought their concern to multifamily group and agreed to a problem solving.

The Problem Question: What can Alex's parents do to support Alex as he reduces his medication dosage? Possible Solutions generated by the group were: 
1) Make a list of early warning symptoms and check in with Alex every few days.

2) Ask Alex if he would share his plan with his roommate to help him monitor his mood and behavior.

3) Create a safety plan in case symptoms return.

4) Meet with Alex’s clinician together with Alex.

5) Ask Alex not to stop his medication.

6) Ask Alex to stay at your home as he goes off his medications.

7) Suggest that Alex keep a journal to help monitor mood and behavior.

The advantages and disadvantages of each suggested solution were discussed by the whole group. After brainstorming, the family (including Alex) agreed to a joint meeting with Alex’s clinician to review early warning symptoms and a plan in case of recurrence of symptoms. During this transition, insomnia recurred but Alex reported it and took medication as needed. After this trial, Alex is now off his antipsychotic medication but chose to continue to take his anti-depressant as it helps keep his mood stable and sleep regular.

Alex is now back to college full-time and has decided on a major in engineering. Approximately 15 months after his first episode, he continues to be symptom free except for occasional insomnia. Since sleep disturbance was one of his earliest symptoms, he responds quickly and uses medication and relaxation techniques. Alex, his parents, school supports and his girlfriend are aware of how to support Alex in staying well. 


\section{Conclusion}

The development of psychosocial treatment approaches for use in the clinical high risk and early phases of schizophrenia and the other major psychotic disorders is clearly at an early stage. However, family psychoeducation and multifamily groups have shown promising outcomes in first episode cases in several studies and multifamily groups appear to have a specific efficacy in earlier phases. The Program of Assertive Community Treatment was also geared to first-episode patients. The result is that there is some basis for expecting that a thoughtful adaptation of these treatment models will have a reasonable chance of achieving efficacy in the period just prior to the onset of the psychotic syndrome. The experience of the authors in preliminary trials is that family psychoeducational treatment is acceptable to families and appears to meet many of their needs. There is theoretical support for the efficacy of these methods, because they have in common a strategy of stress-avoidance, protection and buffering, while the multifamily group format adds an inherent element of social support and network expansion. The next few years could see the steady erosion of the distinction between prepsychotic and psychotic cases, replaced by a continuum of encroaching disability and symptomatology, in which treatments adapted from existing approaches, psychosocial and psychopharmacological, are combined to arrest this disabling, sometimes fatal and profoundly demoralizing set of illnesses. If that occurs, it could well alter the prognosis for what have been until now some of the most dreaded of human afflictions. 


\section{Author Information}

WILLIAM R. MCFARLANE, M.D.

Maine Medical Center Research Institute

Tufts University Medical School

Columbia University, College of Physicians and Surgeons

22 Bramhall Street

Portland, Maine 04012

U.S.A.

mcfarw@mmc.org 


\section{References}

Addington, J., Collins, A., McCleery, A., \& Addington, D. (2005). The role of family work in early psychosis. Schizophrenia Research, 79(1), 77-83.

Amador, X. F., \& David, A. S. (Eds.). (1998). Insight and Psychosis. New York: Oxford.

Amminger, G. P., Schafer, M. R., Papageorgiou, K., Klier, C. M., Cotton, S. M., Harrigan, S. M., Mackinnon, A., McGorry, P. D., \& Berger, G. E.(2010). Long-chain omega-3 fatty acids for indicated prevention of psychotic disorders: a randomized, placebo-controlled trial. Archives of General Psychiatry, 67(2), 146-154.

Anderson, C., Hogarty, G., Bayer, T., \& Needleman, R. (1984). Expressed emotion and social networks of parents of schizophrenic patients. British Journal of Psychiatry, 144, 247255.

Anderson, C., Hogarty, G., \& Reiss, D. (1986). Schizophrenia and the family: A practitioner's guide to psychoeducation and management. New York: Guilford Press.

Baucom, D. H., Shoham, V., Mueser, K. T., Daiuto, A. D., \& Stickle, T. R. (1998). Empirically supported couple and family interventions for marital distress and adult mental health problems. Journal of Consulting and Clinical Psychology, 66, 53-88.

Bebbington, P., \& Kuipers, L. (1994). The predictive utility of expressed emotion in schizophrenia: An aggregate analysis. Psychological Medicine, 24, 707-718.

Bebbington, P., Wilkins, S., Jones, P., Foerster, A., Murray, R., Toone, B., \& Lewis, S. (1993). Life events and psychosis. Initial results from the Camberwell Collaborative Psychosis Study. British Journal of Psychiatry, 162, 72-79.

Becker, T., Leese, M., Clarkson, P., Taylor, R. E., Turner, D., Kleckham, J., \& Thornicroft, G. 
(1998). Links between social network and quality of life: An epidemiologically representative study of psychotic patients in south London. Social Psychiatry and Psychiatric Epidemiology, 33(7), 229-304.

Biegel, D. E., Sales, E., \& Schulz, R. (1991). Family caregiving in chronic illness: Alzheimer's disease, cancer, heart disease, mental illness and stroke. Newbury Park, CA: Sage Publications.

Bird, V., Premkumar, P., Kendall, T., Whittington, C., Mitchell, J., \& Kuipers, E. (2010). Early intervention services, cognitive-behavioural therapy and family intervention in early psychosis: systematic review. British Journal of Psychiatry, 197(5), 350-356.

Brewin, C., MacCarthy, B., Duda, R., \& Vaughn, C. (1991). Attribution and expressed emotion in the relatives of patients with schizophrenia. Journal of Abnormal Psychology, 100, 546-555.

Brown, G. W. (1998). Genetic and population perspectives on life events and depression. Social Psychiatry and Psychiatic Epidemiology, 33(8), 363-372.

Brown, G. W., Birley, J. L. T., \& Wing, J. K. (1972). Influence of family life on the course of schizophrenic disorders: A replication. British Journal of Psychiatry, 121, 241-258.

Brown, G. W., \& Harris, T. (1978). Social origins of depression: A study of psychiatric disorder in women. New York: Free Press.

Butzlaff, R. L., \& Hooley, J. M. (1998). Expressed emotion and psychiatric relapse: a metaanalysis. Archives of General Psychiatry, 55(6), 547-552.

Carter, B., \& McGoldrick, M. (1989). The Changing Family Life Cycle: A Framework for Family Therapy. Boston: Allyn \& Bacon.

Chafetz, L., Havassy, B., \& Arean, P. (1997). Methods for studying course of illness with 
severely mentally ill adults. Issues in Mental Health Nursing, 18(6), 623-638.

Cook, J. A., Leff, H., Blyler, C. R., Gold, P. B., Goldberg, R. W., Mueser, K. T., Burke-Miller, J. (2005). Results of a Multisite Randomized Trial of Supported Employment Interventions for Individuals With Severe Mental Illness. Archives of General Psychiatry, 62(5), 505512.

Dahl, R. E. (2001). Affect regulation, brain development, and behavioral/emotional health in adolescence. CNS Spectrum, 6(1), 60-72.

Das, M. K., Kulhara, P. L., \& Verma, S. K. (1997). Life events preceding relapse of schizophrenia. International Journal of Social Psychiatry, 43(1), 56-63.

Duckworth, K., Nair, V., Patel, J. K., \& Goldfinger, S. M. (1997). Lost time, found hope and sorrow: The search for self, connection and purpose during "awakenings" on the new antipsychotics. Harvard Review of Psychiatry, 5(4), 227-233.

Dyck, D. G., Short, R. A., Hendryx, M. S., Norell, D., Myers, M., Patterson, T., \& McFarlane, W. R. (2000). Management of negative symptoms among patients with schizophrenia attending multiple-family groups. Psychiatric Services, 51(4), 513-519.

Erikson, E. H. (1968). Identity: Youth and Crisis. New York, NY: W.W. Norton \& Company, Inc.

Falloon, I. R. (2003). Family interventions for mental disorders: efficacy and effectiveness. World Psychiatry, 2(1), 20-28.

Falloon, I. R., Boyd, J. L., McGill, C. W., Williamson, M., Razani, J., Moss, H. B., \& Simpson, G. M. (1985a). Family management in the prevention of morbidity of schizophrenia. Clinical outcome of a two-year longitudinal study. Archives of General Psychiatry, 42(9), 887-896. 
Falloon, I. R., \& Pederson, J. (1985b). Family management in the prevention of morbidity of schizophrenia: the adjustment of the family unit. British Journal of Psychiatry, 147, 156163.

Falloon, I. R. H., Boyd, J., \& McGill, C. (1984). Family Care of Schizophrenia. New York: Guilford Press.

Fenton, W. S., Blyler, C. R., \& Heinssen, R. K. (1997). Determinants of medication compliance in schizophrenia: empirical and clinical findings. Schizophrenia Bulletin, 23(4), 637-651. Fjell, A., Bloch Thorsen, G. R., Friis, S., Johannessen, J. O., Larsen, T. K., Lie, K., Lyse, Hanne-Grethe, Melle, I., Simonsen, E., Smeby, N. A., Oxnevad, A. L., McFarlane, W. R., Vaglum, P. \& McGlashan, T. (2007). Multifamily group treatment in a program for patients with first-episode psychosis: experiences from the TIPS project. Psychiatric Services, 58(2), 171-173.

Garrison, V. (1978). Support systems of schizophrenic and nonschizophrenic Puerto Rican women in New York City. Schizophrenia Bulletin, 4, 561-596.

Gioia, D. (2006). Examining work delay in young adults with schizophrenia. American Journal of Psychiatric Rehabilitation, 9, 167-190.

Gleeson, J. F., Cotton, S. M., Alvarez-Jimenez, M., Wade, D., Crisp, K., Newman, B., Spiliotacopoulos, D. \& McGorry, P. D. (2010). Family outcomes from a randomized control trial of relapse prevention therapy in first-episode psychosis. Journal of Clinical Psychiatry, 71(4), 475-483.

Goldstein, M. (1985). Family factors that antedate the onset of schizophrenia and related disorders: The results of a fifteen year prospective longitudinal study. Acta Psychiatrica Scandinavica, 71(Suppl. 319), 7-18. 
Goldstein, M., Rodnick, E., Evans, J., May, P., \& Steinberg, M. (1978). Drug and family therapy in the aftercare treatment of acute schizophrenia. Archives of General Psychiatry, 35, 1169-1177.

Goldstein, M., Rodnick, E., Evans, J., May, P., \& Steinberg, M. R. (1980). Drug and family therapy in the aftercare of acute schizophrenics. Archives of General Psychiatry, 35, 1169-1177.

Gonzalez-Blanch, C., Martin-Munoz, V., Pardo-Garcia, G., Martinez-Garcia, O., AlvarezJimenez, M., Rodriguez-Sanchez, J. M., Vazquez-Barquero, J. L. \& Crespo-Facorro, B. (2010). Effects of family psychoeducation on expressed emotion and burden of care in first-episode psychosis: a prospective observational study. Spanish Journal of Psychology, 13(1), 389-395.

Hammer, M. (1981). Social supports, social networks, and schizophrenia. Schizophrenia Bulletin, 7, 45-57.

Hays, J. C., Krishnan, K. R., George, L. K., \& Blazer, D. G. (1998). Age of first onset of bipolar disorder: demographic, family history, and psychosocial correlates. Depression and Anxiety, 7(2), 76-82.

Heller, T., Roccoforte, J. A., Hsieh, K., Cook, J. A., \& Pickett, S. A. (1997). Benefits of support groups for families of adults with severe mental illness. American Journal of Orthopsychiatry, 67(2), 187-198.

Hirsch, S., Bowen, J., Emami, J., Cramer, P., Jolley, A., Haw, C., \& Dickinson, M. (1996). A one year prospective study of the effect of life events and medication in the aetiology of schizophrenic relapse. British Journal of Psychiatry, 168(1), 49-56.

Hogarty, G., \& Ulrich, R. (1977). Temporal effects of drug and placebo in delaying relapse in 
schizophrenic outpatients. Archives of General Psychiatry, 34, 297-301.

Hogarty, G. E., Anderson, C. M., Reiss, D. J., Kornblith, S. J., Greenwald, D. P., Ulrich, R. F., \& Carter, M. (1991). Family psychoeducation, social skills training, and maintenance chemotherapy in the aftercare treatment of schizophrenia, II: Two-year effects of a controlled study on relapse and adjustment. Archives of General Psychiatry, 48(4), 340347.

Hooley, J., \& Richters, J. E. (1995). Expressed emotion: A developmental perspective. In D. Cicchetti \& S. L. Toth (Eds.), Emotion, Cognition and Representation (Vol. 6, pp. 133166). Rochester: University of Rochester Press.

Hooley, J. M., \& Licht, D. M. (1997). Expressed emotion and causal attributions in the spouses of depressed patients. Journal of Abnormal Psychology, 106(2), 298-306.

Hultman, C. M., Wieselgren, I. M., \& Ohman, A. (1997). Relationships between social support, social coping and life events in the relapse of schizophrenic patients. Scandinavian Journal of Psychology, 38(1), 3-13.

Johannessen, J. O., Larsen, T. K., McGlashan, T., \& Vaglum, P. (2000). Early intervention in psychosis: The TIPS project, a multi-centre study in Scandinavia. Martindale, Brian (Ed); Bateman, Anthony (Ed); Margison, Frank (Ed). (2000). Psychosis: Psychological approaches and their effectiveness.

Johnson, D. (1990). The family's experience of living with mental illness. In H. P. Lefley \& D. L. Johnson (Eds.), Families as allies in treatment of the mentally ill: New directions for mental health professionals (pp. 31-65). Washington, D.C.: American Psychiatric Press.

Keitner, G. I., Drury, L. W., Ryan, C. E., Miller, I. W., Norman, W. H., \& Solomon, D. A. (2002). Multifamily group treatment for major depressive disorder. In W. R. McFarlane 
(Ed.), The Multifamily Group (pp. 244-267). New York: Guilford Press.

Keitner, G. I., \& Miller, I. W. (1993). Combined psychopharmacological and psychosocial treatment for depression. Rhode Island Medicine, 76(8), 415-424.

Kendler, K. S. (1998). Anna-Monika-Prize paper. Major depression and the environment: a psychiatric genetic perspective. Pharmacopsychiatry, 31(1), 5-9.

Kirkbride, J. B., Fearon, P., Morgan, C., Dazzan, P., Morgan, K., Tarrant, J., Lloyd, T., Holloway, J., Hutchinson, G., Leff, J. P., Mallett, R. M., Harrison, G. L., Murray, R. M., \&Jones, P. B. (2006). Heterogeneity in incidence rates of schizophrenia and other psychotic syndromes: findings from the 3-center AeSOP study. Archives of General Psychiatry, 63(3), 250-258.

Kopeikin, H., Marshall, V., \& Goldstein, M. (1983). Stages and impact of crisis-oriented family therapy in the aftercare of acute schizophrenia. In W. R. McFarlane (Ed.), Family Therapy in Schizophrenia (pp. 69-98). New York: Guilford Press.

Kuipers, L. (1994). The measurement of expressed emotion: Its influence on research and clinical practice. International Review of Psychiatry, 6, 187-199.

Leff, J. (1994). Stress reduction in the social environment of schizophrenic patients. Acta Psychiatrica Scandanavica Supplement, 384, 133-139.

Leff, J., Berkowitz, R., Shavit, N., Strachan, A., Glass, I., \& Vaughn, C. (1989). A trial of family therapy v. a relatives group for schizophrenia. British Journal of Psychiatry, 154, 58-66.

Leff, J., Kuipers, L., Berkowitz, R., Eberlein-Vries, R., \& Sturgeon, D. (1982). A controlled trial of social intervention in the families of schizophrenic patients. British Journal of Psychiatry, 141, 121-134.

Leff, J., \& Vaughn, C. (1981). The role of maintenance therapy and relatives' expressed emotion 
in the relapse of schizophrenia: a two-year follow-up. Br. J. Psychiatr., 139, 102-104.

Lefley, H. P. (1996). Family caregiving in mental illness. Thousand Oaks, California: Sage Publications.

Lehman, A. F., Lieberman, J. A., Dixon, L. B., McGlashan, T. H., Miller, A. L., Perkins, D. O., \& Kreyenbuhl, J. (2004). Practice guideline for the treatment of patients with schizophrenia, second edition. American Journal of Psychiatry, 161(2 Suppl), 1-56. Lehman, A. F., Steinwachs, D. M., Buchanan, R., Carpenter, W. T., Dixon, L. B., Fahey, M.,, Fischer, P., Goldman, H.H., Kasper, J., Levine, J., Lyles, A., McGlynn, E., Osher, F., Postrado, L., Rosenheck, R., Scott, J.C., Skinner, E., Thompson, J., \& Zito, J. (1998). Translating research into practice: The Schizophrenia Patient Outcomes Research Team (PORT) treatment recommendations. Schizophrenia Bulletin, 24(1), 1-10.

Lencz, T., Smith, C. W., Auther, A., Correll, C. U., \& Cornblatt, B. (2004). Nonspecific and attenuated negative symptoms in patients at clinical high-risk for schizophrenia. Schizophrenia Research, 68(1), 37-48.

Lichtermann, D., Karbe, E., \& Maier, W. (2000). The genetic epidemiology of schizophrenia and of schizophrenia spectrum disorders. European Archives of Psychiatry and Clinical Neuroscience, 250(6), 304-310.

Lin, N., \& Ensel, W. (1984). Depression-mobility and its social etiology: The role of life events and social support. Journal of Health \& Social Behavior, 25, 176-188.

Link, B. G., Mirotznik, J., \& Cullen, F. T. (1991). The effectiveness of stigma coping orientations: Can negative consequences of mental illness labeling be avoided? Journal of Health and Social Behavior, 32, 302-320.

Lipton, F., Cohen, C., Fischer, E., \& Katz, S. (1981). Schizophrenia: A network crisis. 
Schizophrenia Bulletin 7, 144-151.

Macdonald, E. M., Jackson, H. J., Hayes, R. L., Baglioni, A. J., Jr., \& Madden, C. (1998). Social skill as determinant of social networks and perceived social support in schizophrenia. Schizophrenia Research, 29(3), 275-286.

Malkoff Schwartz, S., Frank, E., Anderson, B., Sherrill, J. T., Siegel, L., Patterson, D., \& Kupfer, D. J. (1998). Stressful life events and social rhythm disruption in the onset of manic and depressive bipolar episodes: a preliminary investigation. Archives of General Psychiatry, 55(8), 702-707.

Mattsson, M., Topor, A., Cullberg, J., \& Forsell, Y. (2008). Association between financial strain, social network and five-year recovery from first episode psychosis. Social Psychiatry and Psychiatric Epidemiology, 43(12), 947-952. doi: 10.1007/s00127-008-0392-3

McFarlane, W. R., \& Cook, W. L. (2007). Family expressed emotion prior to onset of psychosis. Family Process, 46(2), 185-198.

McFarlane, W. R., Cook, W. L., Downing, D., Verdi, M. B., Woodberry, K. A., \& Ruff, A. (2010). Portland identification and early referral: a community-based system for identifying and treating youths at high risk of psychosis. Psychiatric Services, 61(5), 512515.

McFarlane, W. R., Dixon, L., Lukens, E., \& Lucksted, A. (2003). Family psychoeducation and schizophrenia: A review of the literature. Journal of Marital \& Family Therapy, 29(2), 223-245.

McFarlane, W. R., \& Dunne, E. (1991). Family psychoeducation and multi-family groups in the treatment of schizophrenia. Directions in Psychiatry, 11, 2-7.

McFarlane, W. R., Dushay, R. A., Stastny, P., Deakins, S. M., \& et al. (1996). A comparison of 
two levels of family-aided assertive community treatment. Psychiatric Services, 47(7), 744-750.

McFarlane, W. R., Dushay, R.A., Deakins, S.M., Stastny, P., Lukens, E.P., Toran, J. \& Link, B. (2000). Employment outcomes in Family-aided Assertive Community Treatment. American Journal of Orthopsychiatry, 70(2), 203-214.

McFarlane, W. R., Link, B., Dushay, R., Marchal, J., \& Crilly, J. (1995). Psychoeducational multiple family groups: Four-year relapse outcome in schizophrenia. Family Process, 34(2), 127-144.

McFarlane, W. R., Lukens, E., Link, B., Dushay, R., Deakins, S. A., Newmark, M., Dunne, E. J., Horen, B., \& Toran, J. (1995). Multiple-family groups and psychoeducation in the treatment of schizophrenia. Archives of General Psychiatry, 52(8), 679-687.

McFarlane, W. R., \& Lukens, E. P. (1998). Insight, families, and education: An exploration of the role of attribution in clinical outcome. Amador, Xavier F (Ed); David, Anthony S (Ed), (1998). Insight and psychosis. (pp. 317-331). xviii, NY, US: Oxford University Press.

McFarlane, W. R., Stastny, P., \& Deakins, S. (1992). Family-aided assertive community treatment: A comprehensive rehabilitation and intensive case management approach for persons with schizophrenic disorders. New Directions in Mental Health Services, 53, 4354.

McGlashan, T. H., Zipursky, R. B., Perkins, D., Addington, J., Miller, T. J., Woods, S. W., \& Breier, A. (2006). Randomized, double-blind trial of olanzapine versus placebo in patients prodromally symptomatic for psychosis. American Journal of Psychiatry, 163(5), 790-799. 
McGorry, P. D., McFarlane, C., Patton, G. C., Bell, R., Hibbert, M. E., Jackson, H. J., \& Bowes, G. (1995). The prevalence of prodromal features of schizophrenia in adolescence: a preliminary survey. Acta Psychiatr Scand, 92(4), 241-249.

McGorry, P. D., Mihalopoulos, C., Henry, L., Dakis, J., Jackson, H., Flaum, M. \& Karoly, R. (1995). Spurious precision: Procedural validity of diagnostic assessment in psychotic disorders. The American Journal of Psychiatry, 152(2), 220 - 223.

Meneghelli, A., Alpi, A., Pafumi, N., Patelli, G., Preti, A., \& Cocchi, A. (2011). Expressed emotion in first-episode schizophrenia and in ultra high-risk patients: Results from the Programma2000 (Milan, Italy). Psychiatry Research.

Miklowitz, Strachan, A., Goldstein, M., Doane, J., Snyder, K., Hogarty, G., \& Falloon, I. (1986). Expressed emotion and communication deviance in the families of schizophrenics. Journal of Abnormal Psychology, 95(1), D60-66.

Miklowitz, D., Velligan, D., Goldstein, M., Nuechterlein, K. M., Ranlett, G., \& Doane, J. (1991, May). Communication deviance in families of schizophrenic and manic patients. Journal of Abnormal Psychology, 100(2), 163-173.

Miklowitz, D. J., Frank, E., \& George, E. L. (1996). New psychosocial treatments for the outpatient management of bipolar disorder. Psychopharmacology Bulletin, 32, 613-621.

Miklowitz, D. J., \& Goldstein, M. J. (1997). Bipolar Disorder: A Family-focused Treatment Approach. New York: Guilford Press.

Murray-Swank, A., \& Dixon, L. (2004). Family psychoeducation as an evidence-based practice. CNS Spectrums, 9(12), 905.

Nordentoft, M., Thorup, A., Petersen, L., Ohlenschlaeger, J., Melau, M., Christensen, T. O. \& Jeppesen, P. (2006). Transition rates from schizotypal disorder to psychotic disorder for 
first-contact patients included in the OPUS trial. A randomized clinical trial of integrated treatment and standard treatment. Schizophrenia Research, 83(1), 29-40.

Nuechterlein, K. H., Dawson, M. E., Ventura, J., Gitlin, M., Subotnik, K. L., Snyder, K. S. \& Bartzokis, G. (1994). The vulnerability/stress model of schizophrenic relapse: a longitudinal study. Acta Psychiatrica Scandanavica Supplement, 382, 58-64.

O'Brien, M. P., Zinberg, J. L., Ho, L., Rudd, A., Kopelowicz, A., Daley, M., Bearden, C. E. \& Cannon, T. D. (2009). Family problem solving interactions and 6-month symptomatic and functional outcomes in youth at ultra-high risk for psychosis and with recent onset psychotic symptoms: a longitudinal study. Schizophrenia Research, 107(2-3), 198-205.

Pallanti, S., Quercioli, L., \& Pazzagli, A. (1997). Relapse in young paranoid schizophrenic patients: a prospective study of stressful life events, P300 measures, and coping. American Journal of Psychiatry, 154(6), 792-798.

Pattison, E., Llama, R., \& Hurd, G. (1979). Social network mediation of anxiety. Psychiatric Annals, 9, 56-67.

Penninx, B. W. J. H., Kriegsman, D. M. W., van Eijk, J. T. M., Boeke, A. J. P., \& Deeg, F. J. H. (1996). Differential effect of social support on the course of chronic disease: A criterionbased literature review. Families, Systems and Health, 14(2), 223-244.

Petersen, L., Nordentoft, M., Jeppesen, P., Ohlenschlaeger, J., Thorup, A., Christensen, T. O., Krarup, G., Dahlstrom, J., Haastrup, B. \& Jorgensen, P. (2005). Improving 1-year outcome in first-episode psychosis: OPUS trial. British Journal of Psychiatry, 187(Suppl48), s98-s103.

Peterson, E. C., \& Docherty, N. M. (2004). Expressed Emotion, Attribution, and Control in Parents of Schizophrenic Patients. [Article]. Psychiatry: Interpersonal \& Biological 
Processes, 67(2), 197-207.

Phelan, J. C., Bromet, E. J., \& Link, B. B. (1998). Psychiatric illness and family stigma. Schizophrenia Bulletin, 24(1), 115-126.

Pitschel-Walz, G., Leucht, S., Bauml, J., Kissling, W., \& Engel, R. R. (2001). The effect of family interventions in relapse and rehospitalization in schizophrenia: A meta-analysis. Schizophrenia Bulletin, 27(1), 73-92.

Randolph, E. T., Eth, S., S.M., G., Paz, G. G., Leong, G. B., Shaner, A. L. \& Liberman, R. P. (1994). Behavioral family management in schizophrenia: Outcome of a clinic-based intervention. British Journal of Psychiatry, 164(501-506).

Schooler, N. R., Keith, S. J., Severe, J. B., Matthews, S. M., Bellack, A. S., Glick, I. D., Hargreaves, W.A., Kane, J.M. , Ninan, P.T. , Frances, A ., Jacobs, M. , Lieberman, J.A., Mance, R ., Simpson, G.M., Woerner, M. G. (1997). Relapse and rehospitalization during maintenance treatment of schizophrenia: The effects of dose reduction and family treatment. Archives of General Psychiatry, 54(5), 453-463.

Schooler, N. R., Levine, J., \& Severe, J. B. e. a. (1980). Prevention of relapse in schizophrenia: An evaluation of fluphenazine decanoate. Archives of General Psychiatry, 37, 16-24.

Singer, M., \& Wynne, L. (1985). Schizophrenics, families and communication disorders. In R. Cancro \& S. R. Dean (Eds.), Research in the schizophrenic disorders (Vol. 1, pp. 231247). New York: Spectrum Publications.

Solomon, P., \& Draine, J. (1995a). Adaptive coping among family members of persons with serious mental illness. Psychiatric Services, 46(11), 1156-1160.

Solomon, P., \& Draine, J. (1995b). Subjective burden among family members of mentally ill adults: relation to stress, coping, and adaptation. American Journal of Orthopsychiatry, 
65(3), 419-427.

Steinberg, H., \& Durell, J. (1968). A stressful social situation as a precipitant of schizophrenia. British Journal of Psychiatry, 114, 1097-1105.

Sun, D., Phillips, L., Velakoulis, D., Yung, A., McGorry, P. D., Wood, S. J., van Erp, T. G., Thompson, P. M., Toga, A. W., Cannon, T. D., \& Pantelis, C. (2009). Progressive brain structural changes mapped as psychosis develops in 'at risk' individuals. Schizophr Res, 108(1-3), 85-92.

Takeuchi, D. T., Chung, R. C., Lin, K. M., Shen, H., Kurasaki, K., Chun, C. A., \& Sue, S. (1998). Lifetime and twelve-month prevalence rates of major depressive episodes and dysthymia among Chinese Americans in Los Angeles. Am J Psychiatry, 155(10), 14071414.

Tarrier, N., Barrowclough, C., Vaughn, C., Bamrah, J., Porceddu, K., Watts, S., \& Freeman, H. (1989). Community management of schizophrenia A two-year follow-up of a behavioral intervention with families. British Journal of Psychiatry, 154, 625-628.

Tienari, P., Wahlberg, K.-E., \& Wynne, L. C. (2006). Finnish Adoption Study of Schizophrenia: Implications for Family Interventions. [Article]. Families, Systems \& Health: The Journal of Collaborative Family HealthCare, 24(4), 442-451.

Tienari, P. A., Wynne, L. C., Sorri, A., Lahti, I., Läksy, K., Moring, J., Naarala, M., Nieminen, P., \& Wahlberg, K. E. (2004). Genotype-environment interaction in schizophrenia spectrum disorder. British Journal of Psychiatry, 184, 216-222. Tolsdorf, C. (1976). Social networks, support and coping: An explanatory study. Family Process, 15, 407-417. van Os, J., Fahy, T. A., Bebbington, P., Jones, P., Wilkins, S., Sham, P., Russell, A., Gilvarry, K., Lewis, S. \& Toone, B. (1994). The influence of life events on the subsequent course 
of psychotic illness. A prospective follow-up of the Camberwell Collaborative Psychosis Study. Psychological Medicine, 24(2), 503-513.

Vaughn, C. E., \& Leff, J. P. (1976). The influence of family and social factors on the course of psychiatric illness: A comparison of schizophrenic and depressed neurotic patients. British Journal of Psychiatry, 129, 125-137.

Vaughn, C. E., Snyder, K. S., Jones, S., Freeman, W. B., \& Falloon, I. R. (1984). Family factors in schizophrenia relapse: A replication in California of British research on expressed emotion. Archives of General Psychiatry,, 42, 1169-1177.

Veling, W., Hoek, H. W., \& Mackenbach, J. P. (2008). Perceived discrimination and the risk of schizophrenia in ethnic minorities: a case-control study. Social Psychiatry and Psychiatic Epidemiology, 43(12), 953-959.

Wagener, D. K., Hogarty, G. E., Goldstein, M. J., Asarnow, R. F., \& Browne, A. (1986). Information processing and communication deviance in schizophrenic patients and their mothers. Psychiatry Research, 18, 365-377.

Zubin, J., \& Spring, B. (1977). Vulnerability: A new view of schizophrenia. Journal of Abnormal Psychology, 86, 103-126.

Zubin, J., Steinhauer, S. R., \& Condray, R. (1992). Vulnerability to relapse in schizophrenia. British Journal of Psychiatry, 161 (suppl. 18), 13-18. 